\title{
To See or Not to See...
}

\author{
Dr. Wolfgang Fink \\ California Institute of Technology, Pasadena, CA
}

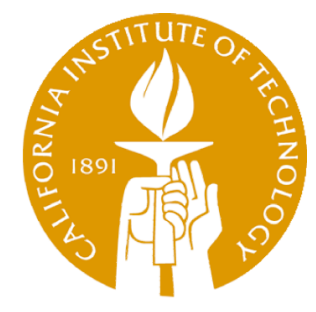

Vision is the primary sense used in daily life. How do we "see" the world? Do we actually "see" it or rather "perceive" it? Or is it one and the same thing? How do people with optical eye defects perceive the world? Can normally sighted people partake in their experience? If you are blind or become blind, are you blind forever?

On Earth and in the spaceflight environment, there are many effects and conditions that may impair your vision or lead to irreversible vision loss or blindness, especially if undetected. The human eye and vision system can be likened to a camera consisting of an optical lens system (cornea and eye lens), film or sensor (retina), and an image-processing unit (retina and visual cortex). The malfunctioning of only one of these components will impair your vision.

This talk will touch on the above topics and have (some of) the answers.
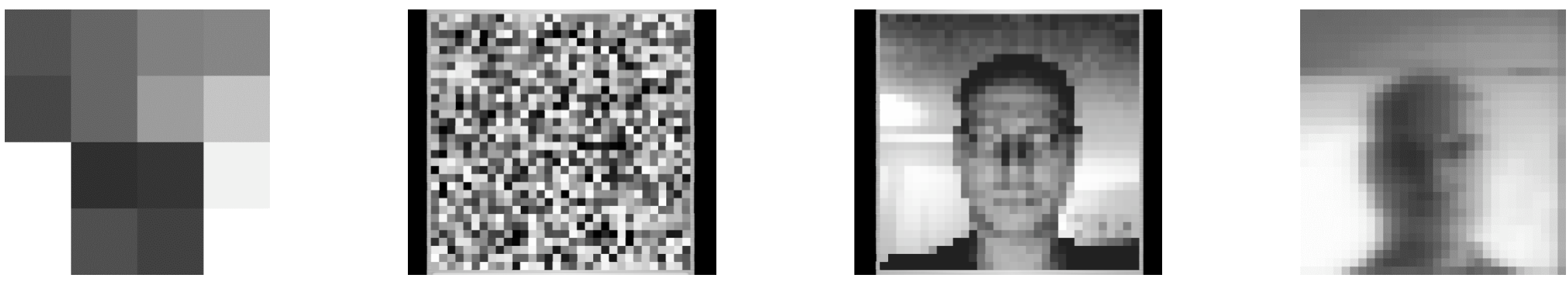


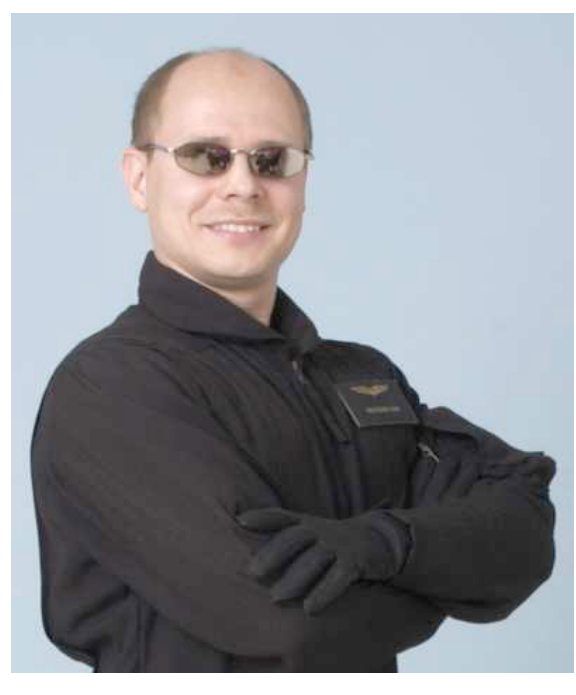

Wolfgang Fink, Ph.D., is a Visiting Associate in Physics at the California Institute of Technology, Research Associate Professor of both Ophthalmology and Neurological Surgery at the University of Southern California, and Senior Researcher at NASA's Jet Propulsion Laboratory. Dr. Fink conducts research in the areas of biomedicine, computer optimized design, computational field geology, and autonomous planetary and space exploration. He is the founder and head of the Visual and Autonomous Exploration Systems Research Laboratory (http://autonomy.caltech.edu) at Caltech. Dr. Fink has been conducting interdisciplinary research at the interface of physics and medical sciences over many years with focus on human vision, and is leading research and development efforts towards tier-scalable reconnaissance mission architectures for autonomous planetary and space exploration.

Dr. Wolfgang Fink is the recipient of the 2002 NASA Spaceflight Awareness Launch Honoree Award in support of human space flight, and the co-recipient of the "Humie Silver Award" for demonstrating Human Competitive Performance in the Automated Design of Space Systems from the Genetic and Evolutionary Computation Conference (GECCO) 2005. In 2006, Dr. Fink won the Congress on Evolutionary Computation (CEC) 2006 international "Huygens Probe" optimization competition, held at the World Congress on Computational Intelligence (WCCl) 2006 in Vancouver, BC, Canada. He has over 120 publications to his name.

Dr. Wolfgang Fink earned his Ph.D. in Theoretical Physics in 1997 from the Eberhard-Karls-University of Tübingen, Germany, and his M.S. in Theoretical Physics, Physical Chemistry, and Astronomy in 1993 from the Georg-August-University of Göttingen, Germany.

Dr. Fink is a concert pianist and holds a Commercial Pilot's License for Rotorcraft.

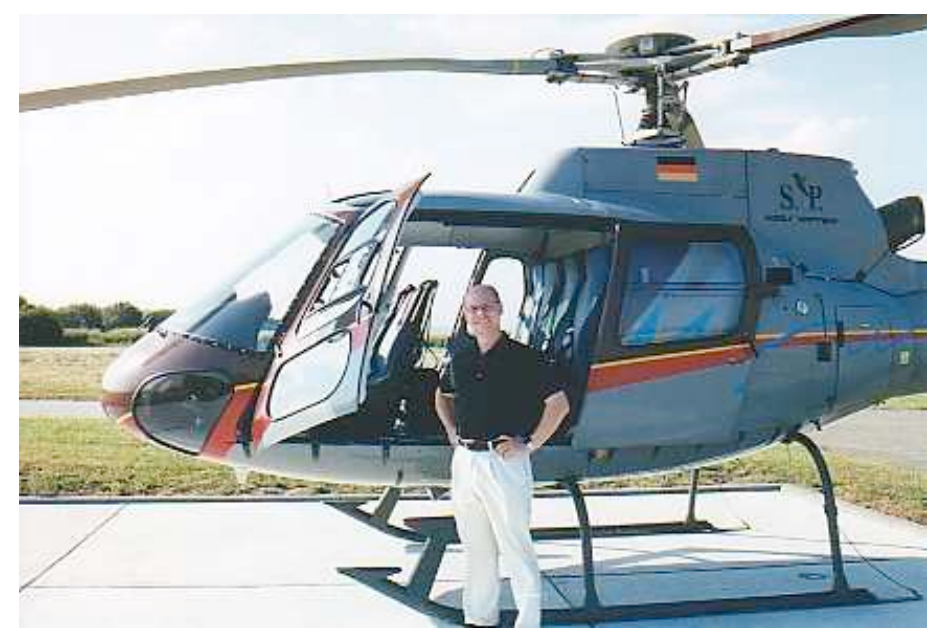

